\title{
TRANSCRIAÇÕES A PARTIR DE UMA CONVERSA COM ERNESTO OROZA
}

\section{ENTREVISTA}

LOPES, Maria Fernanda de Mello ${ }^{1}$

PINHEIRO, Amálio ${ }^{2}$

LOPES, Maria Fernanda de Mello. PINHEIRO, Amálio. Transcriações a partir de uma conversa com Ernesto Oroza. Revista Científica Multidisciplinar Núcleo do Conhecimento. Ano 05, Ed. 11, Vol. 18, pp. 23-35. Novembro de 2020. ISSN: 24480959, Link de acesso: https://www.nucleodoconhecimento.com.br/comunicacao/ernesto-oroza

\section{RESUMO}

Entrevista realizada com o artista e designer cubano Ernesto Oroza. Trata-se de uma conversa que se deu em mais de um momento e que, por isso, ao parecer, mais do que uma transcrição, requer o conceito de transcriação, conforme desenvolvido por Haroldo de Campos, por não consistir mais apenas em uma entrevista fiel ao seu primeiro roteiro, que foi anteriormente usado de maneira desviada da planejada. A conversação gira em torno da pesquisa de Oroza: enquanto comenta sua prática, o designer traça também um pano de fundo sobre o contexto cubano, discorrendo acerca de suas ferramentas, seus métodos de criação e de investigação. As perguntas

${ }^{1}$ Doutoranda e Mestre em Comunicação e Semiótica pela Pontifícia Universidade Católica de São Paulo (PUC-SP), Mestre pelo Programa de Estudos Independentes (PEI) do Museu de Arte Contemporânea de Barcelona (MACBA), vinculado à Universidade Autônoma de Barcelona (UAB). Membra do Grupo de Pesquisa Comunicação Cultura Barroco e Mestiçagem da PUC-SP.

2 Orientador. Doutorado em Comunicação e Semiótica. Mestrado em Literatura. Especialização em Literatura Hispano -americana. Graduação em Direito. 
se ativeram a algumas de suas produções, em especial o projeto Desobediência Tecnológica, exposto no ano de 2015 na Caixa Cultural de Recife, um trabalho que é aqui pensado em relação à ideia de gambiarra no Brasil.

Palavras-chave: Ernesto Oroza, desobediência tecnológica, gambiarra, processos culturais.

\section{CONSIDERAÇÕES INICIAIS}

Ernesto Oroza nasceu em Havana, Cuba, onde também desenvolveu seus estudos em design gráfico e posteriormente em design industrial. Hoje vive em Saint-Étienne, na França, onde trabalha como responsável pelo Departamento de Pós-Graduação em Design e Pesquisa na Escola de Arte e Design de Saint-Étienne e como diretor editorial da revista Azimuts; e também é curador de uma das exposições centrais da próxima Bienal de Design de Saint-Étienne (BIDSE21). Foi professor visitante em Les Ateliers, na Escola Nacional Superior de Criação Industrial em Paris, e professor do Instituto Politécnico de Design de Havana. Em sua pesquisa, lança olhares e proposições que lidam com a realidade de maneira não ortodoxa, por meio de temas atinentes à arquitetura, ao design de interiores e de objetos. Possui vários livros publicados, sendo um de seus últimos títulos "Notes sur la maison moirée: (ou un urbanisme pour des villes qui se vidente)" (2013). Já participou de várias residências artísticas e recebeu diversos prêmios, como o World Space Creators Awards, no Japão, e a bolsa Guggenheim, em Nova York. Participou de exposições em galerias e centros culturais pelo mundo. No Brasil, a Caixa Cultural de Recife expôs seu projeto Desobediência Tecnológica no ano de 2015.

Este texto, formatado boa parte como um diálogo, visto que parte de uma proposta de entrevista, é fruto de algumas conversas travadas entre a pesquisadora e o artista e designer cubano Ernesto Oroza. Os diálogos transcorreram sempre por via eletrônica, tendo em vista o distanciamento social necessário por conta da COVID-19, bem como a distância geográfica, dado que Oroza falou desde Saint-Éttiene, na França, e a autora, de São Paulo. Como o contato se deu por meio de variados diálogos - entre e-mails, videoconferências, reuniões com o Grupo de Pesquisa, além da investigação 
da entrevistadora -, pareceu mais adequado chamar este texto de "transcriação" (CAMPOS, 2015), em vez da simples transcrição, de uma entrevista. A partir de uma primeira conversa que, apesar de roteirizada, não aconteceu da maneira planejada, somaram-se outras conversas junto de mais estudos e reflexões. A infidelidade para com o roteiro original, torna proveitoso aqui o conceito de Haroldo ("transcriação"), que nesta proposta atua como uma forma de relação em progresso, e não como aplicação fechada, e que se dá em vários níveis. Primeiro, pelo desvio da ideia tradicional e fiel de entrevista; depois, pela própria tradução da língua, já que boa parte da conversa aconteceu em espanhol; por fim, também, pelo conteúdo das ideias trabalhadas que, ao trazer à tona o deslocamento de padrões, não deixa de ser também mais uma possibilidade de desvio enquanto caminho de criação e reelaboração diferencial e incorporante de um acontecimento.

Por mais que não se proponha aqui a tradução de nenhum trabalho seu em específico, falar de um processo de criação como o de Ernesto Oroza implica uma tradução do falar sobre seu trabalho, o que por sua vez carrega uma poética que necessariamente impregna a escuta, o pensamento e a escrita da entrevistadora. Pareceu então que uma boa medida seria acompanharmo-nos da ideia de "tradução/transcriação/transculturação/" de Haroldo de Campos (2015, p. 155). Há de se aclarar que nos valemos do autor brasileiro a fim de propor uma relação com seu complexo conceito de tradução criativa, apresentado de saída em termos polissêmicos; Haroldo fala de tradução de poesia (o que pode ser entendido também de maneira ampliada, abarcando a poética dos objetos); isto difere do que aqui se propõe: falar de uma tradução das ideias que levam à poesia contida nos trabalhos de Oroza.

\section{REDESENHO PARA ALGUMAS CONVERSAS}

Maria Fernanda: Hoje você mora na França?

Ernesto Oroza: Sim, vivo em Saint Ettiénne, ao sul de Lyon. É uma cidade pequena, com algumas relações interessantes. Além do futebol, tem uma escola de design, a Escola Superior de Arte e Design, e uma bienal de design importante, provavelmente 
a mais antiga da França. Fui convidado para trabalhar no departamento de design na Pós-graduação, também estou na curadoria de uma das exposições da próxima bienal de design e sou editor da revista Azimuts. Logo que cheguei, começou a pandemia. Antes disso, morei em Miami por 13 anos.

MF: Noto, na sua prática como artista, um posicionamento que busca estar em relação direta com o ambiente onde se está inserido, para então elaborar o trabalho por uma perspectiva inclusiva e aplicar as suas lentes e ferramentas. Uma espécie de modo de operar relacional, que investiga as quebras de padrões dos desenhos preconcebidos levando em conta o contexto/ambiente, tanto a arquitetura e o urbanismo quando o design. Um olhar que se propõe crítico e ao mesmo tempo afetivo, no sentido espinosano.

O: Sim, pois não me interessa definir o que eu faço. Posso trabalhar nos mais variados tipos de espaço. Quando saio de Havana e vou morar em Miami, um colecionador me pergunta: Como a sua prática é muito local, o que você vai fazer agora? E me dei conta de que me farão esta pergunta muitas vezes. Eu elaboro ferramentas [para meu trabalho] - o contexto pode mudar, entra e sai. Pode ser Havana, Recife, Miami.

MF: Percebo uma certa expansão no seu olhar investigativo, e ela me parece bastante coerente. Inicialmente, você parece se concentrar mais nos objetos do cotidiano (como no projeto Desobediência Tecnológica), depois abarca as moradias (como no projeto Arquitectura de la Necesidad) e então abre-se para temas ligados ao urbanismo e às populações imigrantes (projeto Pequeño Haitt). Você poderia comentar um pouco sobre a relação com o ambiente no seu trabalho?

O: Exatamente, eu continuo fazendo a mesma coisa. Interesso-me por variados tipos de processo, tais como assuntos ligados a excessos, populações, contaminação. Por exemplo, interesso-me por uma espécie de peixe invasor, que foi introduzido em Cuba no final da década de 1990, chamado Claria. Por ser uma ilha, o ecossistema cubano é muito frágil e ficou prejudicado com a disseminação deste animal, pois além de se alimentar na água, também sai para a terra e caça aves. É um peixe que caminha! Ainda, sobre a Claria, costumo acompanhar o site revolico.com, sobre compra e venda 
em Cuba. É uma das formas de acompanhar de longe alguns processos na ilha. Há sempre uma descrição detalhada dos produtos, então comecei a notar a recorrência da palavra Claria. Pesquisando mais, entendi que se tratava de "cara de Claria", uma referência à parte frontal de um tipo de caminhão chinês que tem estado bastante difundido em Cuba. A invasão da Claria em vários aspectos.

Há também diversos outros tipos de processos que me parecem interessantes - redes entre pessoas, questões relacionadas às novas tecnologias, como el paquete semana/3].

MF: Eu entrei em contato com o seu trabalho por meio do projeto Desobediência Tecnológica, que é inclusive uma referência recorrente nos estudos que têm sido desenvolvidos sobre a gambiarra. Interessou-me especialmente a maneira com a qual você consegue sistematizar e inventariar elementos de uma prática tão fluida. Você pode comentar um pouco sobre esse projeto? Existe um acervo onde se encontram esses objetos?

O: Sim. Para pensar em algum tipo de sistematização, busquei algumas recorrências nestes reparos. Se prestar atenção, sempre há algum indício, traços que aparecem mais de uma vez. Eu tenho esse olhar para uma certa sistematização de recorrências nos meus trabalhos. Isso me possibilita pensar em possibilidades de sistematizar padrões que se repetem.

E eu começo a teorizar sobre a prática do meu trabalho para dialogar com as pessoas. Comecei a ter conflitos com a algumas instituições cubanas, arquitetos, dentre outros; muitos não aprovavam e muitas vezes tinham uma espécie de vergonha de que eu mostrasse essa precariedade. Em várias situações, disseram que meu trabalho era apenas uma questão de "gosto" ou algo kitsch. Por conta disso, conversei com muita gente, o que foi muito importante para o trabalho.

Tenho um grande arquivo, são vários acervos, e como tive que me mover bastante, estão em diferentes lugares. Algumas coisas se perderam, mas ainda tenho muitas. Sempre trago comigo alguns destes objetos e continuo modificando e reinventando 
em cima deles. Uma vez me perguntaram se, pela quantidade de coisas que tenho, eu faria um museu. Não me interessa ter um museu! Eu me apaixonei por esta ideia da reinvenção.

MF: A gambiarra como uma coisa viva.

O: Claro.

MF: Esse trabalho está concentrado nos objetos, em sua maioria dos anos 1990 em Cuba? Você acha que essa prática continua como um hábito, incorporando as novas tecnologias?

O: As práticas já existiam. Eu comecei a prestar atenção a essas práticas nos anos 1990, quando me formei [como designer gráfico e de produtos]. Também nos 90 se intensificou a crise, por conta da queda do Muro de Berlim e da dissolução da URSS [grande parceira comercial de Cuba na época]. Muitas destas desobediências aconteciam na minha casa. Essas coisas ainda são frequentes, mas talvez menos, e também de maneiras diferentes, porque vão entrando novos objetos e isso muda a paisagem. Antes circulavam mais objetos soviéticos [e com pouca variedade de marcas e modelos], produtos como a Coca-Cola entraram na Ilha em um momento posterior, pela demanda dos turistas que queriam tomar cuba-libre.

Nos 90 todos usavam os mesmos objetos, das casas mais burguesas às pequenas casas. A possibilidade de adquirir bens de consumo também interfere no ambiente. Modifica a arquitetura, como no caso das famílias que vão aumentando e continuam habitando a mesma casa, que então sofre novas adaptações. As cores disponíveis para a pintura dessas casas - conforme vão entrando mais produtos de uma gama mais variada, aumentam em quantidade e em brilho.

Agora, com a questão da pandemia de COVID-19, isso outra vez vai afetar Cuba, pois o turismo é uma fonte econômica muito importante e foi extremamente prejudicado. As pessoas estão novamente desesperadas. Nos anos 1990, a precariedade era tamanha que alguns cubanos se voluntariaram para cuidar de animais selvagens, pois, como os zoológicos estavam com problemas, as pessoas podiam ficar 
temporariamente com os filhotes, e para isso ganhavam comida. Por isso, tinha gente doida para ter um pequeno leão em casa. Situações como estas foram retratadas também no cinema cubano.

MF: Como foi a experiência de trazer este projeto [Desobediência Tecnológica] para o Brasil, na exposição da Caixa Cultural no Recife em 2015?

O: Foi uma surpresa super bonita! Eu estava já há muitos anos em Miami, e ver as pessoas saindo de suas casas e caminhando para ver o trabalho exposto foi emocionante. Pude conversar bastante com as pessoas na exposição, e também me relacionar com os vizinhos. Eu me apaixonei por Recife. Desenvolvi uma série fotográfica lá, em uma favela chamada Brasília Teimosa. Também tive contato com alguns acadêmicos e pesquisadores. Eu já conhecia um pouco da cultura brasileira, poder visitar foi um sonho realizado.

MF: E as possíveis relações entre gambiarra e a desobediência tecnológica? [Parte das informações da resposta abaixo têm como fonte uma entrevista dada por Oroza em 2015, por ocasião da sua exposição em Recife[4].]

O: Quando eu cheguei era como se tivesse um déjà-vu. Várias soluções são as mesmas, acredito que porque as necessidades também são as mesmas. Já vi o mesmo tipo de remediação em diferentes lugares do mundo. Eu não conhecia a palavra gambiarra, ela me foi apresentada por alguns alunos meus em Paris.

MF: Poderia me dar informações sobre os relógios reparados? [Catálogo da exposição Caixa Cultural, projeto Desobediência Tecnológica, fig. n. 58] (OROZA, 2015, p.47) 
Figura 1 - Ernesto Oroza, fotografia, 2015
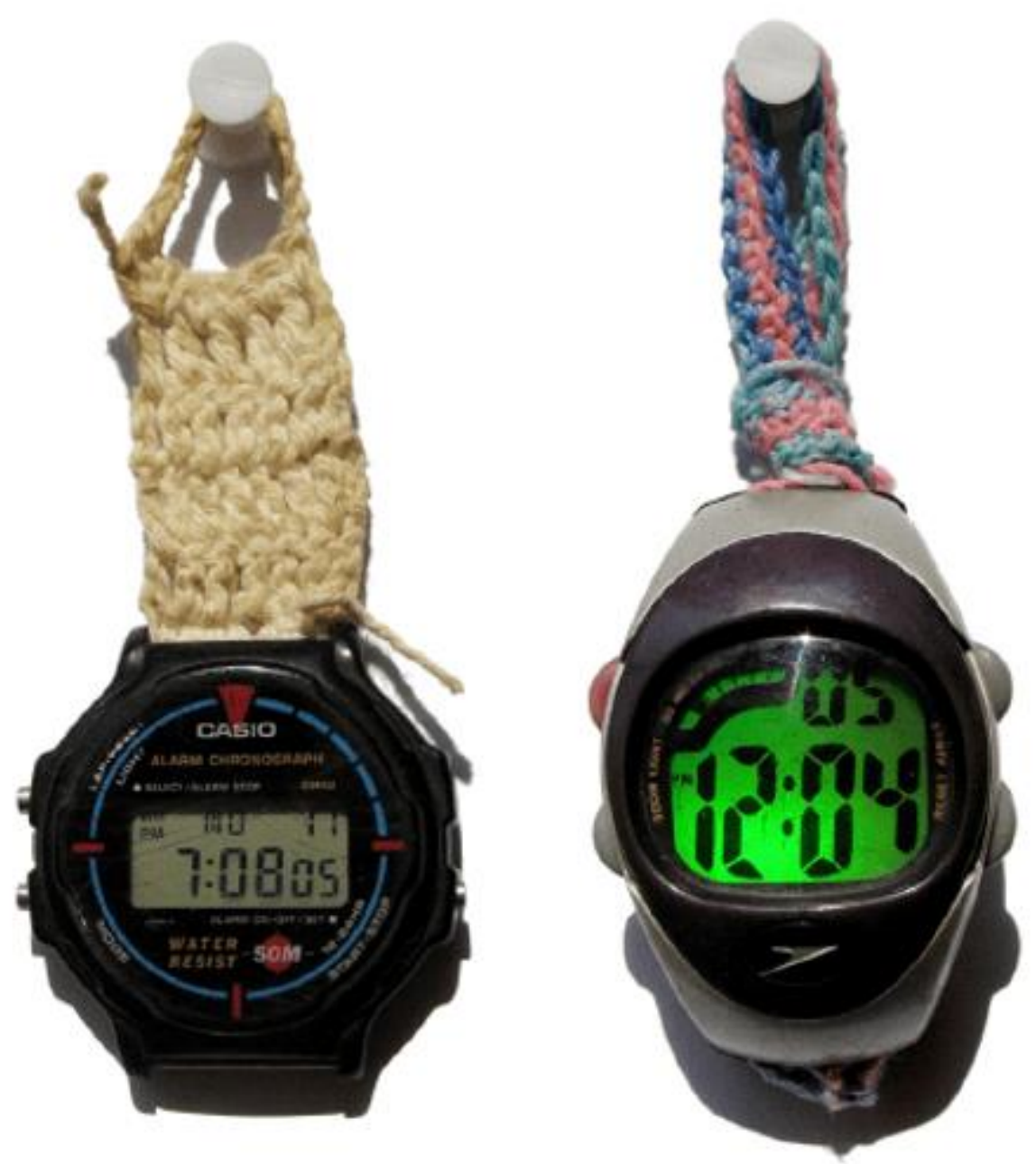

Fonte: Catálogo da exposição Desobediência Tecnológica, Caixa Cultural do Recife, 2015

O: Os relógios estão em um dos meus acervos, e são os únicos relógios do acervo. Foram feitos pela minha segunda sogra, Zulema. Ela fez para ver as horas enquanto cozinhava, ficavam pendurados na parede. Ela era bastante habilidosa com as mãos, fazia crochê e coisas deste tipo. Perguntei a ela o que era aquele relógio e ela, a princípio, desconversou. Muitas vezes, num primeiro momento, as pessoas em Cuba são um pouco tímidas para falar desses reparos, há uma espécie de vergonha da precariedade, da pobreza, mas quando elas percebem o meu interesse pelas criações ficam orgulhosas e conversam mais. Como minha sogra sabia do meu trabalho, 
acabou me dando o relógio. Eu havia dito que the daria um novo relógio de parede, mas, na semana seguinte, já havia o segundo relógio [também improvisado] no mesmo lugar daquele primeiro. Para realizar essa foto [com os dois relógios um ao lado do outro] me inspirei naquele trabalho do Félix González-Torres, Untitled (Perfect Lovers). Inicialmente eu chamava essa foto de "amantes imperfectos".

Figura 2 - Felix Gonzalez-Torres, “Untitled” (Perfect Lovers), 1991

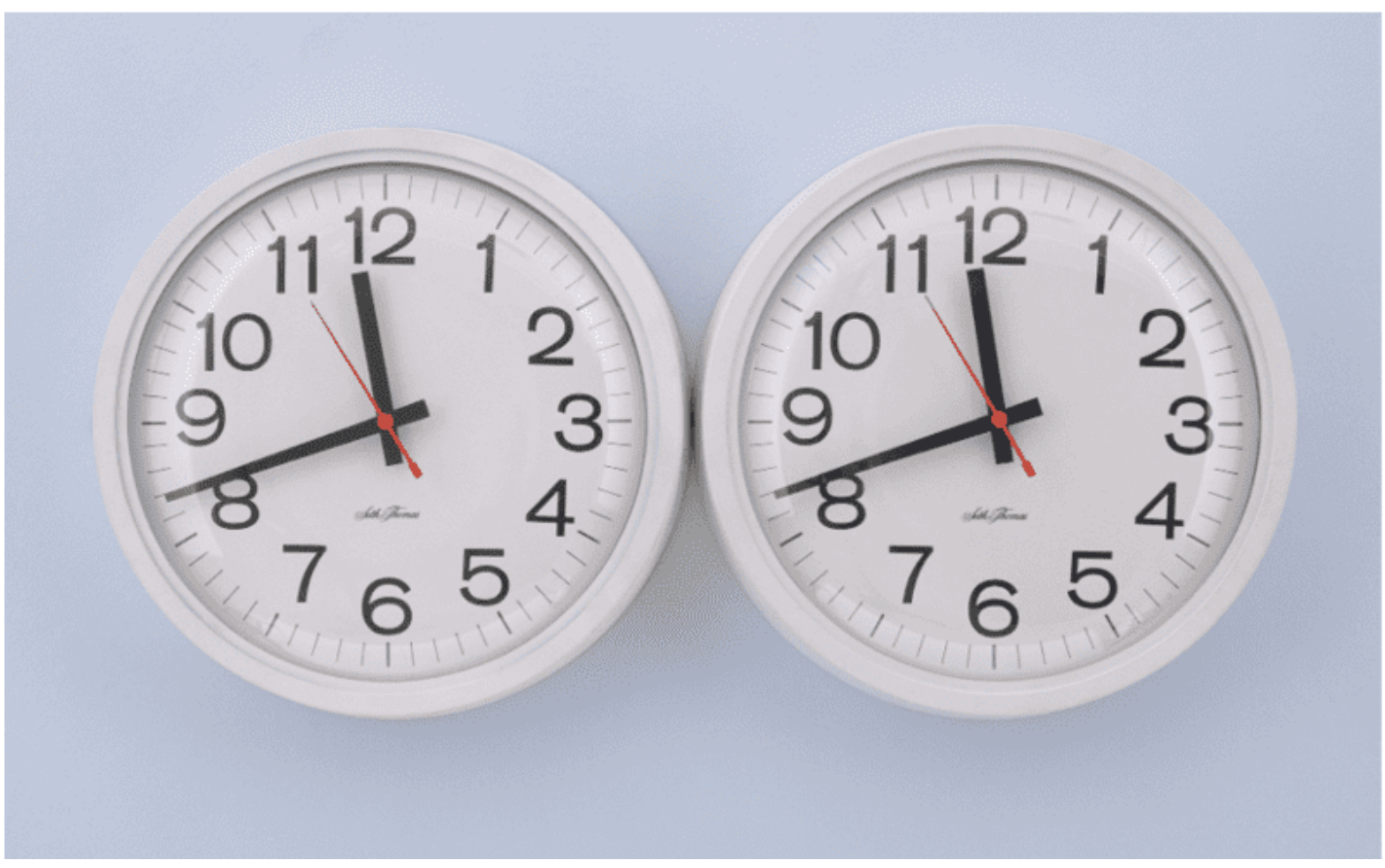

Fonte: Moma, 2020

Eu tive duas sogras. A primeira era uma maestra normalita, com uma visão um pouco atrasada da função da mulher na sociedade, ensinava trabalhos domésticos na escola às meninas. Isso antes da Revolução. Mas ela resolvia as coisas de maneiras muito inusitadas, estava sempre inventando coisas. Pude aprender muito com ela. Em uma certa época, estava muito empenhado em fazer projetos, estava havia meses trabalhando intensamente, por horas a fio, perdendo peso. Eu sonhava com o design italiano radical dos anos 1960-1970, até que um dia ela coloca sobre a mesa um ventilador quebrado e começa a tentar consertar. Não me disse nada e logo percebi que o que eu estava fazendo era um lixo. Eu me dei conta de que estava enganado 
ao seguir com aqueles projetos, pois eu queria ter uma visão sincera da realidade. A partir disso, comecei a prestar atenção nesse tipo de práticas [gambiarras] e a trabalhar junto com a minha sogra nessas soluções cotidianas. Passei inclusive a entender isto como prática de design. Então passo a registrar essas soluções, começando pela minha casa, depois nos vizinhos, por Havana, e depois viajo pela ilha nessa busca. Muitos dos objetos e práticas que registrei são considerados ilegais pela lei cubana, por isso as pessoas não aparecem nas fotos. Penso acerca da produção destas práticas [gambiarras] em contextos diferentes do cubano, não sei como é no Brasil, me pergunto se por exemplo, professores universitários e médicos desenvolvem este tipo de prática, aqui temos muitos casos.

MF: Sei que há uma questão de acesso, de remuneração, e que imaginamos que os médicos e professores de universidades, os já estabelecidos, não os emergentes, costumam ter melhores condições econômicas. Mas, além disso, noto algumas pessoas que, ademais de terem uma estabilidade, não deixam de ter necessidade de resolver as coisas e as fazem de maneiras pouco usuais. Acredito se tratar de algo que também atua no plano do desejo. Este tipo de conduta eu noto nas mais variadas gambiarras e situações que observo e tenho notícia. Então, sim, evidentemente é uma questão de necessidade material, econômica, mas não acho que se encerra nisso. Nas favelas e nas regiões mais economicamente desfavorecidas, é evidente que as gambiarras serão mais frequentes. Esses processos de se pensar para além dos padrões (de marca, design, beleza, mercado, uso, função, e mais tantos outros ligados ao status quo) tendem a ser mais intensos em lugares entendidos como menos centrais, de maneira geral. Este tipo pensamento faz parte do que venho pesquisando[5], a ideia de que as maneiras de se pensar, como as que produzem gambiarras, estão também diluídas por aí. Estão em todas as partes em que se foge do pensamento hegemônico, frequente nas sociedades de tradição ocidental.

Voltando ao trabalho "Desobediência Tecnológica", no texto do catálogo da exposição [OROZA, 2015], há termo "salto imaginativo", você poderia comentar um pouco esta ideia? 
O: Acredito que a ideia de "salto imaginativo" tem seus próprios saltos e aparições dentro do texto "Desobediência Tecnológica" [OROZA, 2015], que já foi publicado de diferentes maneiras. Existem blocos introdutórios que não estão presentes em todas as publicações.

Esta ideia é um tipo de contraproposta a um trabalho que eu estava fazendo com uma equipe de franceses que queria falar sobre os fluxos nas casas cubanas, mas por uma perspectiva que me pareceu bastante equivocada e da qual, por isso, me desvinculei.

"Salto imaginativo" tem a ver com uma conversa mais ampla com a cultura industrial. Uma crítica ao novo, ao perfeito, ligado a ideias do design relacionados à escola Ulm, na Alemanha, dirigida por Max Bill, acerca do paradigma de máxima beleza e objeto perfeito.

Nesses saltos, não se trata apenas de criar algo novo: é algo que traz consigo alguma relação nova. Novas relações sociais emergem quando Che Guevara convoca: trabajador, construye tu propia maquinaria. Esses objetos, que primeiramente eu chamava de "objetos discretos", "objetos sensíveis", têm a potencialidade de mudar a forma de consumir, e não só a cultura material. Essas modificações, ao borrarem esses padrões, são também um feito político, um salto de funcionalidade.

Prefiro pensar que em uma forma há muitas outras possibilidades de relação inclusive - para os designers, mas não apenas para estes -, e que das aberturas para modificações há um convite ao outro. Claro que essas possibilidades de reuso e reparação sempre existiram. Mas nesse período ocorre uma intensificação, inclusive do compartilhamento desses saberes acerca dos objetos técnicos. Os objetos que quebravam eram abertos para serem reparados, e com isso sistemas fechados tornam-se abertos, sistemas que poderiam parecer impenetráveis. Assim, os objetos começaram a ser desmontados, reparados, e, em um momento posterior, reinventados nas casas. Esse conhecimento foi sendo compartilhado entre as pessoas, práticas que vão contra a lógica consumista do capitalismo. Eu me inspiro em Augusto Boal, que dizia que todo mundo pode fazer teatro, inclusive os atores, para pensar que todo mundo pode fazer projeto, inclusive os designers. 
MF: Você conhece os jericos[6] brasileiros? Possuem alguns pontos de proximidade com os rikimbill[7] cubano. É uma prática usual, especialmente no sul do Brasil: veículos em geral construídos com peças de outros veículos, para trabalhar em propriedades rurais. Mas também se fazem festivais e corridas desta modalidade de "veículo gambiarra".

O: Interessante. Também é interessante notar como a regulamentação pode afetar a paisagem. Em Cuba, havia uma lei que permitia que os automóveis fossem alterados apenas em 40\%. Esse limite subiu depois para 60\%. Isso leva a alterações significativas e que ao mesmo tempo são muito difíceis de serem quantificadas. Me lembrei dos caminhões em Cuba que chamamos de cara de palo [cara de pau em português] e com isso me veio à mente o trabalho de Hélio Oiticica, por conta de Cara de Cavalo (figura associada ao crime e referência presente em alguns trabalhos do artista, como na bandeira-poema "Seja marginal. Seja Herói"). Dá para tecer associações sobre a ideia de marginal, estar à margem de certos padrões.

MF: Você está atualmente desenvolvendo algum projeto?

O: Tenho pensado sobre a prática musical do repente junto à desobediência tecnológica. Estou trabalhando em um filme que fala sobre isso. Uma mesma prática, em diferentes lugares, como vem a se desenvolver de distintos modos. Eu me concentro em duas cidades: em Hileah, Miami, nos EUA, e Pinar del Río, em Cuba. Para os repentistas trabalharem seus improvisos eu sugiro palavras que normalmente são estranhas ao repertório usual. Reflito então acerca do repente em diferentes lugares, e sobre as relações dos repentistas com a métrica. Me interessam questões ligadas ao ritmo nas práticas da Desobediência Tecnológica e no repente. Isso também tem a ver com a cultura cigana, andaluza, africana, que se relacionam com os processos culturais em Cuba, México, Brasil, por exemplo.

MF: Sim, questões ligadas também aos estudos sobre mestiçagem. Tem alguns pontos em comum com a pesquisa que desenvolvemos no Grupo de Pesquisa Comunicação e Cultura: Barroco, Oralidades e Mestiçagem[8]. Inclusive, estudamos bastante autores cubanos como Severo Sarduy e Lezama Lima. 
O: Sim, são autores-chave para mim. Como a ideia de retombée de Sarduy. E também [o poeta Luis de] Góngora, pai intelectual de Lezama. Gosto de um poema em que ele trabalha a questão da tradução do latim da frase necessitats caret lege, traduzida para o espanhol como la necesidad tiene cara de hereje, mas que poderia ter sido algo como la necesidad carece de ley.[9] A necessidade foi estigmatizada pela cultura ocidental: se você diz que tem alguma necessidade, você é visto como fraco. Mas entender que você precisa de algo pode ser um momento de liberdade, no sentido trazido por Espinosa, Hegel, Engels...

\section{REFERÊNCIAS}

CAMPOS, Haroldo de. Transcriação. Org. Marcelo Tápia e Thelma Médici. São Paulo: Perspectiva, 2015.

JORNAL MARCO ZERO. Brasília Teimosa, periferia de Havana, 2015. Disponível em: < https://marcozero.org/brasilia-teimosa-periferia-de-havana/. Acesso em: nov., 2020.

OROZA, Ernesto. Desobediência Tecnológica. Disponível em: <http://www.desobedienciatecnologica.net/>. Acesso em: fev. 2019.

Rikimbili. Disponível em: $\quad<$ https://www.ernestooroza.com/rikimbili/>. Acesso em: nov., 2020. . Desobediência tecnológica. Catálogo da exposição Caixa Cultural de Recife, 2015. Disponível em: <<http://museo.com.br/catalogodesobedienciatecnologica.pdf>. Acesso em: fev. 2019.

GONZALES-TORRES, Félix, Untilted, (perfect lovers), in: Tempo. Catálogo da exposição. HERKENHOFF, Paulo et al. MOMA, Nova York, 2002.

Untilted, (perfect lovers), 1991. Disponível em: <<https://www.moma.org/collection/works/81074 >. Acesso em: jun. 2020. 
MELLO LOPES, Maria Fernanda de. Gambiarra como processo: uma antropofagia latino-americana. Dissertação de Mestrado apresentada no departamento de Comunicação e Semiótica da PUC-SP. São Paulo, 2019. Disponível em: << https://tede2.pucsp.br/handle/handle/22878> Acesso em nov. 2020.

\section{APÊNDICE - REFERÊNCIAS DE NOTA DE RODAPÉ}

3. El paquete semanal ou apenas el paquete é uma compilação de material digital de cerca de um terabyte, comercializado em Cuba no mercado informal por meio de HD's externos. Por conta do alto custo e das dificuldades da população cubana para acessar à internet, parte do conteúdo, em geral ligado a entretenimento, que poderia ser acessado pela internet, o é por meio destas compilações. Como no caso de desenhos animados, séries, filmes, dentre outros tipos de conteúdo audiovisual. Estes HD's são atualizados semanalmente por quem trabalha com a sua distribuição.

4. Matéria "Brasília Teimosa, periferia de Havana", veiculada em 2015. Disponível em: https://marcozero.org/brasilia-teimosa-periferia-de-havana/

5. Para maiores informações a este respeito ver "Gambiarra como processo: uma antropofagia latino-americana' (LOPES, 2019)

6. É possível ver uma gravação de arrancadão, corrida, de jericos em: https://www.youtube.com/watch?v=a91GYiudSRk

7. Rikimbili é o nome usado em Cuba para se referir a bicicletas que são artesanalmente modificadas, tornando-se bicicletas movida a combustível, dentre uma série de outras alterações, adaptações e reparos. Maiores informações podem ser encontrada em postagem do blog de Ernesto Oroza, disponível em: https://www.ernestooroza.com/rikimbili/ bem como em algumas das figuras contidas no Catálogo da Exposição Desobediência Tecnológica (2015, p, 48 - 49).

8. Grupo de pesquisa vinculado ao Programa de Pós Graduação em Comunicação e Semiótica da PUC-SP, liderado pelo Prof. Dr. Amálio Pinheiro. 
9. Oroza desenvolve esta ideia em seu blog. Para maiores informações consultar =: http://www.ernestooroza.com/la-necesidad-tiene-cara-de-hereje/

Enviado: Novembro, 2020.

Aprovado: Novembro, 2020. 